\title{
Self-Concept and Performance in Shorthand: A Case Study of Secretarial Students
}

\author{
ABURIYA A. DIANA AZEESI ROGER BABA BLONCH ADOMBILLA \\ Bolgatanga Polytechnic, Department of Secretaryship and Management Studies, Box 767, Bolgatanga, Ghana
}

\begin{abstract}
This study sought to ascertain the effects of students' self-concept of academic ability on their academic performance in shorthand. The respondents were mainly secretarial students. After giving a background to the study, research questions and corresponding research objectives were developed. Relevant literature was reviewed and a research methodology developed. The systematic random sampling was used and the research instrument was questionnaire. Analysis was carried out using the Statistical Package for Social Sciences (SPSS).The study discovered that, shorthand students have basic qualification for the study of the course and are self-motivated. The study concluded that, shorthand is an interesting course that motivates young people with requisite qualification. The study also elucidated that shorthand as a course be taught at pre-tertiary level and level 100 at the polytechnics. DOI: $10.7176 / \mathrm{NMMC} / 87-03$
\end{abstract}

Publication date: January $31^{\text {st }} 2020$

\subsection{Background}

Most students who enrol in Secretarial Studies at either certificate or diploma levels do not get certificates at the end of their training because they fail in Shorthand, a key subject in the training of secretaries. Eddy (2002) opined that the performance in national examinations in shorthand today continues to dwindle as a result of students' lack of interest to excel. A student's attitude towards a subject greatly influences performance. It affects the individual's organised manner of thinking, feeling and reaction to a study subject. Also Hamchek (1971) observes that an individual's attitude towards a subject will influence their self-concept of academic ability. Therefore, while Shorthand remains the bed-rock upon which the secretary career is established by imparting on learners initiative, innovation and organisational skill, the failure rate is so high that there is the need to explore ways to reverse the trend.

A cross-sectional survey of the targeted population of this study shows that the scale of poor performance in Shorthand is about $90 \%$. With most trainees looking forward to a secretarial career, this state poses a great concern to all stakeholders because of its manpower implications. Poor performance in Shorthand is an indicator that, the commitment to attaining the career goal might either be lacking or has been dimmed by either internal or external influences. Attitude, whether intrinsically or extrinsically motivated plays a major role in influencing performance at any stage.

Furthermore, students' self-concept in terms of academic ability is not only influence by the learners' selfconcept profiles but also by those of the significant others especially the subject teachers and fellow students. So long as the curriculum continues to emphasise the teaching of Shorthand for prospective Secretaries, it is imperative to ensure that the products of the process are well qualified to pursue their career path. This is the academic lacuna that this study hopes to fill. This study therefore is a modest attempt to examine attitude as a contributing factor to poor performance in shorthand. This study seeks to ascertain whether students' self-concept of academic ability has an effect on their academic performance in shorthand.

Keywords: Self-motivation, shorthand, students, performance, examination

\subsection{The Theory of Shorthand}

Beryl Pratt in her book "What is Pitman's Shorthand?" writing on the performance of pitman shorthand in the United Kingdom states that dictation cannot teach any shorthand theory, outline or phrase. According to her, for one to do well in Shorthand, they must learn and concentrate on basic phrases. One must also increase reading practice from printed shorthand instruction books to consolidate knowledge of outlines. Berly advises those learning Shorthand to endeavour to write as fast as a person can speak as this will assist in improving the transcription speed. Henry in his book, "A Manual of Current Shorthand, Orthographic and Phonetic", says that, learners have to improve in the English language as well as master spelling in other to effectively learn Shorthand. He advises learners to sharpen their powers of concentration and alertness which are both essential attributes for shorthand writing. In this case, also learners have been advised to occasionally practice speed of 20 vword per minute (wpm) faster.

Over the years, Chief Examiners for Shorthand at Bolgatanga Polytechnic have raised various issues concerning the performance of students in shorthand examinations. In their reports, the Chief Examiners have indicated that a lot needs to be done in the Polytechnic to help candidates do well in their shorthand examinations. According to the 2010, 2011, 2012, 2013, 2014 Chief Examiner's reports, most candidates' scripts displayed lack 
of mastery of the subject. This shows that the candidates lacked shorthand skills. In the same report, the Chief Examiners also noted that some candidates had not achieved the speed required for examination. The Chief Examiners indicate that such candidates sat for the examinations when they were not ready and consequently failed, as compared to other subjects taken in these semesters. The Chief Examiners reports also identify incomplete transcription as contributing to poor performance in these examinations. Wrong transcriptions and wrong outlines are also a common feature in the candidates' work presented for marking. This according to the Chief Examiners indicates lack of enough reading and practise. It also shows that the candidates have not mastered the Shorthand theory.

Moreover, anyone willing to learn Shorthand must have some specific skills also known as the entry behaviour. Entry behaviours are necessary specific skills that students must have prior to beginning an instruction. It is not a list of things that students can do, but the specific skills that they must have in order to begin a certain course. Different levels have different entry requirements. The entry behaviour of learners affects the speed with which a teacher can introduce new material, the amount of reading of primary sources you can expect and the level of critical analysis you can demand. In practical courses, students need certain forms of literacy to enable them succeed. One of them is tool literacy, or the ability to understand and use the practical and conceptual tools relevant to education and the areas of work and professional life that the individual expects to inhabit. One of the entry behaviour expected of a shorthand student is mastery in the English Language which is also displayed in the candidates' scripts during marking. The Chief Examiners indicate that mastery of English Language is a must for one to do well in Shorthand since dictation passages are written and dictated using the English Language.

Practical exposure to students in the relevant areas and a sound theoretical background provides a modern industry oriented education. It aims at producing trained professionals who can successfully meet the demands of the various industries. A more practical and applied way of teaching can improve the relevance of work. Practical skills are an essential part of competence in some disciplines. As Well as developing these practical skills, good laboratory and practical work also help students develop expertise in critical enquiry, problem solving, experimental design, data analysis and presentation, and a long list of important academic and professional abilities. Emphasis in teaching practical subjects should be on students' active involvement in doing the practices. Practical process skills such as careful observation, interpreting, predicting events, designing experimenting, organizing information and reporting and generalization will be acquired. Good quality work promotes the engagement and interest of the learner as well as developing a range of skills and conceptual understanding.

\subsection{Methodology}

The study used the descriptive design due to its implicit significance on statistics of diverse issues (Ngechu 2006). It also seeks information that describes existing phenomena such as perceptions, attitudes, behaviour or values of individuals (Muganda and Muganda, 2003). This thus justified the need to use this approach to elicit the factors is the influencing the poor performance of shorthand students. The population for this study consisted of Secretarial students in the department of Secretaryship and Management Studies of the Bolgatanga Polytechnic. The systematic random sampling was used to determine the population for the study. Also the research instrument for the study was questionnaire. The content of the questionnaire sought information on the bio data and self-concept of shorthand performance among students. The data gathered were analysed both qualitatively and quantitatively. Quantitative data which was mainly from close ended items were coded and keyed into the computer using the statistical package for social sciences (SPSS) version 20 to calculate frequencies and percentages. Qualitative data mainly came from the open ended item. The items were coded, keyed into the computer and analysed using the same version of the SPSS.

\subsection{Results and discussions}

\subsection{Bio Data of Students}

This aspect of the study sought to find out the biographic statistics of the respondent s. This was deemed necessary because of the correlations between the respondents and the variables and under investigation. The results are presented in figure 1 . 


\section{Percentage}

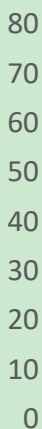

70

60

50

40

30

20

10

0

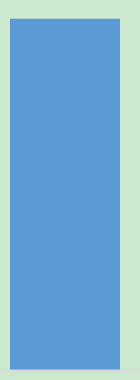

$16-30$

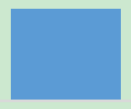

$31-45$

3

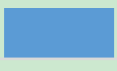

45-60

Figure 1: Age bracket of student

The results in Table 1 show that, $71.2 \%$ of the respondents were aged $16-30$ years of age while $18.6 \%$ were aged between 31 - 45 years of age. Only 10.2\% of the respondents were aged between 46 and 60 . This suggests that shorthand is undertaken by young people. Therefore, by researchers' estimation, young people studying shorthand are expected to do better giving their youthfulness and energy.

\subsection{Academic Qualification of Students}

The results indicate that, $57.6 \%$ of the respondents had attained secondary education, while only $10.2 \%$ had University education, $32.2 \%$ had other academic qualifications. This illustrates that, the majority of the shorthand students have attained secondary education. The shorthand students therefore have the basic knowledge required for the effective study of shorthand.

Table 1: Academic Qualification of respondents

\begin{tabular}{lll} 
Academic Qualification & Frequency & Per cent \\
\hline Secondary & 34 & 57.6 \\
University & 6 & 10.2 \\
Others & 19 & 32.2 \\
\hline Total & 59 & 100.0 \\
\hline
\end{tabular}

\subsection{Professional Qualification of Students}

As in Table 2, the results show that, $49.2 \%$ of the respondents had no qualifications while $32.2 \%$ had secretarial training, $13.6 \%$ had a diploma and $5.1 \%$ had Certificate of participation in entrepreneurship. This suggests that, student enter the polytechnic to pursue shorthand without previous knowledge.

Table 2: Professional qualification of students

\begin{tabular}{lll} 
Professional Qualification & Frequency & Per cent \\
\hline 3.3 Secretary & 19 & 32.2 \\
Diploma & 8 & 13.6 \\
Entrepreneur & 3 & 5.1 \\
No Qualification & 29 & 49.2 \\
\hline Total & 59 & 100.0 \\
\hline
\end{tabular}

\subsection{The effects of students' self-concept of academic ability on their academic performance}

The responses as in Table 3 shows that $31 \%$ of the respondents believed that they do not have what it takes to excel in shorthand. This displays a negative perception of their self-concept of academic worth. They do not consider themselves intelligent enough to excel in shorthand. While a majority of the respondents $69 \%$ however believe they can do well. Since a person tends to act like the sort of individual he conceives himself to be, it is expected that this group of students approach their work with optimism and high hopes. The majority of the students are self-motivated so as to be able to do well. The respondents were equally asked to indicate their love for the shorthand and whether they preferred other subjects' to shorthand. The response indicated that $61 \%$ of the population love shorthand. This shows that, the students are not negatively disposed towards the subject. While the researchers' assumptions are that, love for a subject should translate to hard work and devotion to the subject 
and consequently good performance, the results confirmed it.

Table 3: Students' Self-concept of Academic Ability on their Performance

\begin{tabular}{|l|l|l|l|l|l|l|l|l|}
\hline Statement & Yes & F & $\%$ & No & F & $\%$ & TF & T \% \\
\hline I believe I do not have what it takes to do well in shorthand & & 41 & 69 & & 18 & 31 & 59 & 100 \\
\hline I have love for shorthand & & 36 & 61 & & 23 & 39 & 59 & 100 \\
\hline
\end{tabular}

\subsection{Shorthand Teachers' Perception of Students' Ability on the Subject}

The respondents were asked of their perception of students' ability to study shorthand. The results were analysed by merging "strongly disagree" and "disagree" to be disagree and "strongly agree" and "agree" to be agree and "unsure" to be neutral.

Table 4: Shorthand Teachers' Perception of Students' Ability on the Subject

\begin{tabular}{|c|c|c|c|c|c|c|c|c|c|c|c|c|c|c|c|c|c|}
\hline $\begin{array}{l}\text { Variable } \\
\text { (statement) }\end{array}$ & SD & $\mathbf{F}$ & $\%$ & D & $\mathbf{F}$ & $\%$ & US & $\mathbf{F}$ & $\%$ & $\mathbf{A}$ & $\mathbf{F}$ & $\%$ & $\mathbf{S A}$ & $\mathbf{F}$ & $\%$ & TF & T\% \\
\hline $\begin{array}{lr}\text { Students } & \text { are } \\
\text { capable } & \text { of } \\
\text { studying shorthand }\end{array}$ & & 2 & 3.4 & & 0 & 0 & & 2 & 3.4 & & 31 & 52.5 & & 24 & 40.7 & 59 & 100 \\
\hline $\begin{array}{l}\text { Students prefer } \\
\text { shorthand to other } \\
\text { subjects }\end{array}$ & & 0 & 0 & & 0 & 0 & & 0 & 0 & & 18 & 30.5 & & 41 & 69.5 & 59 & 100 \\
\hline $\begin{array}{l}\text { Shorthand is } \\
\text { generally feared by } \\
\text { students }\end{array}$ & & 0 & 0 & & 0 & 0 & & 5 & 8.5 & & 35 & 59.3 & & 19 & 32.2 & 59 & 100 \\
\hline $\begin{array}{l}\text { Generally students } \\
\text { do well in } \\
\text { shorthand }\end{array}$ & & 4 & 6.8 & & 5 & 8.5 & & & & & 27 & 45.7 & & 23 & 39 & 59 & 100 \\
\hline $\begin{array}{l}\text { The practical } \\
\text { oriented nature of } \\
\text { shorthand } \\
\text { engenders interest } \\
\text { in the subject }\end{array}$ & & 2 & 3.4 & & 5 & 8.5 & & 4 & 6.8 & & 35 & 59.3 & & 13 & 22 & 59 & 100 \\
\hline $\begin{array}{lr}\text { The theoretical } \\
\text { aspect } \\
\text { shorthand } \\
\text { students }\end{array}$ & & 2 & 3.4 & & 4 & 6.8 & & 2 & 3.4 & & 21 & 35.6 & & 30 & 50.8 & 59 & 100 \\
\hline $\begin{array}{lr}\text { The content } & \text { of } \\
\text { shorthand } & \text { is } \\
\text { difficult } & \text { for } \\
\text { students } & \\
\text { comprehension } & \\
\end{array}$ & & 3 & 5 & & 5 & 8.5 & & 2 & 3.4 & & 27 & 45.8 & & 22 & 37.3 & 59 & 100 \\
\hline $\begin{array}{l}\text { Lack of basis at the } \\
\text { lower level of } \\
\text { education makes } \\
\text { learning shorthand } \\
\text { difficult }\end{array}$ & & 12 & 20.3 & & 13 & 22.1 & & & & & 18 & 30.5 & & 16 & 27.1 & 59 & 100 \\
\hline $\begin{array}{l}\text { Changes in } \\
\text { shorthand outlines } \\
\text { poses learning } \\
\text { difficulties }\end{array}$ & & 4 & 6.8 & & 6 & 10.2 & & 5 & 8.5 & & 24 & 40.6 & & 20 & 33.9 & 59 & 100 \\
\hline & & & & & & & & & & & & & & & & & \\
\hline
\end{tabular}

\section{Source: Field Survey, August, 2018}

As can be seen in Table $452.5 \%$ agreed and 40.7\% strongly agreed ( $93.2 \%$ cumulative) that shorthand students are capable of studying the subject; all the respondents agreed that they have preference for the subject representing $100 \%$ while $59.3 \%$ agreed and $32.2 \%$ strongly agreed ( $91.5 \%$ cumulative) that the subject is feared by students. Also, $45.7 \%$ agreed and $39 \%$ strongly agreed $(84.7 \%$ cumulative) that generally students perform well in shorthand; $59.3 \%$ and $22 \%$ agreed and strongly agreed $(81.3 \%$ cumulative $)$ that the practical nature of the subject engenders interest in the subject; $35.6 \%$ and $50.8 \%$ agreed and strongly agreed $(86.4 \%$ cumulative) that the theoretical aspect scares students while $45.8 \%$ and $37.3 \%$ agreed and strongly agreed ( $83.1 \%$ cumulative) that the content is difficult for students to understand. Further, $30.5 \%$ and $27.1 \%$ agreed and strongly agreed $(57.6 \%$ cumulative) that lack of previous knowledge makes the learning of the subject difficult whereas $40.6 \%$ and $33.9 \%$ agreed and strongly agreed ( $74.5 \%$ cumulative) that variations in outline pose learning difficulties.

This analysis shows that generally students have a positive self-concept towards the study of shorthand as a course. It can also be deduced from this interpretation that not only do students have positive self-concept but the 
ability to study the course. Suffice to generalize that students desire to study the course is huge and their chances of success is enormous. A student's attitude towards a subject greatly influences performance .It affects the individual's organised manner of thinking, feeling and reaction to a study subject (Eddy, 2002). Also Hamchek (1971) observes that an individual's attitude towards a subject will influence their self-concept of academic ability.

\subsection{Interest in Shorthand}

An endeavour was made to ascertain ways of generating interest in shorthand. The respondents were accordingly asked. The responses are shown in Table 5

Table 5: Interest in shorthand by students

\begin{tabular}{|c|l|l|l|l|l|l|l|l|}
\hline Ways (variable) & Yes & $\mathrm{F}$ & $\%$ & No & $\mathrm{F}$ & $\%$ & $\mathrm{TF}$ & $\mathrm{T} \%$ \\
\hline 1. Linking Lesson to previous Knowledge & & 33 & 66 & & 26 & 44 & 59 & 100 \\
\hline $\begin{array}{l}\text { 2. } \\
\text { Availability of Teaching Learning } \\
\text { Materials }\end{array}$ & 44 & 75.6 & & 15 & 25.4 & 59 & 100 \\
\hline 3. Practicalising the Teaching of Shorthand & & 46 & 78 & & 13 & 22 & 59 & 100 \\
\hline 4. Using appropriate methodology & & 38 & 64.4 & & 21 & 35.6 & 59 & 100 \\
\hline $\begin{array}{l}\text { Adequate timeframe for the teaching of } \\
\text { Shorthand }\end{array}$ & 41 & 69.5 & & 18 & 30.5 & 59 & 100 \\
\hline 6. & & 36 & 61 & & 23 & 39 & 59 & 100 \\
\hline 7. Availability of shorthand teachers & & 45 & 76.3 & & 14 & 23.7 & 59 & 100 \\
\hline 8. Positive attitude of shorthand teachers & & 34 & 57.6 & & 25 & 42.4 & 59 & 100 \\
\hline
\end{tabular}

Table 5 indicates that, out of the total number of 59 respondents engaged in the study, $66 \%$ saw linking lessons to previous knowledge as a means of generating interest while $44 \%$ thought otherwise, $75.6 \%$ saw availability of teaching learning materials to be a way of generating interest while $25.4 \%$ said no to it, practicalising the teaching of shorthand registered $78 \%$ yes and $22 \%$ no and using appropriate technology registered $64.4 \%$ yes and $35.6 \%$ no. Also, adequate timeframe for the teaching of shorthand registered $69.5 \%$ yes and $30.5 \%$ no, simulation registered $61 \%$ yes and $39 \%$ no, availability of shorthand teachers registered $76.3 \%$ yes and $23.7 \%$ no and positive attitude of shorthand teachers registered $57.6 \%$ yes and $42.4 \%$ no.

This analysis shows that diversity of ways exist for generating interest of students in shorthand which include linking lessons to previous knowledge (66\%), availability of teaching learning materials $(75.6 \%)$, practicalising the teaching of shorthand (78), using appropriate technology (64.4\%), adequate timeframe for the teaching of shorthand $(69.5 \%)$, simulation (61\%), availability of shorthand teachers $(76.3 \%)$ and positive attitude of shorthand teachers $(57.6 \%)$

It can, therefore, be generalized that students' interest in shorthand is contingent on the variables stated above. Attitude, whether intrinsically or extrinsically motivated plays a major role in influencing performance at any stage. Hamchek (1971) observes that an individual's attitude towards a subject will influence their self-concept of academic ability. Therefore, while Shorthand remains the bed-rock upon which the secretary career is established by imparting on learners initiative, innovation and organisational skill, the failure rate is so high that there is the need to explore ways to reverse the trend

\section{Finding, conclusions and recommendations}

The study established that, students engaged in studying shorthand are mostly young people and are capable of excelling by virtue of their age and zeal. The study also discovered that, shorthand students have basic qualification required for the study of the subject even though the majority of the students do not have previous knowledge of the subject. The study further unearths the self-motivated nature of shorthand students and their preference and love for it.The study also discovered that the use appropriate technology and the positive attitude of both shorthand teachers and students engenders interest in the subject and that the chances of success on the part of the students of shorthand is enormous.

The study concluded that, shorthand is an interesting subject loved by motivated young people. These young people have the requisite requirement necessary for the pursuance of shorthand notwithstanding the fact they lack previous knowledge of the subject.

The study recommended among others that, the National Board for Professional and Technician Examination (NABPTEX) should draw up a programme for Polytechnics to educate level 100 students offering Secretarial and Management Programme on the importance of Shorthand to their career as Secretaries in order for them to appreciate the course. The Ministry of Education and for that the Ghana Education Service should endeavour to introduce shorthand in the second cycle institutions especially technical schools, since it does not only focus on the signs and symbols but encapsulates speed and various aspect of the English Language such as spellings, pronunciation, phonetics, part of speech etc. The study further recommends that, the Ghana Education Service should provide adequate teaching and learning materials like textbooks, tape recorders, CDs etc for the teaching 
and learning of shorthand to sustain the interest and motivation of shorthand students. Teachers of shorthand should continually upgrade themselves to sustain the interest of students in the subject.

\section{Acknowledgement}

The support in the form of research facilities and the cooperation of all those who provided responses to the research survey from the Bolgatanga polytechnic, as well as all references made from journals are duly acknowledged.

\section{References}

Books, Journals and Reports

Bolgatanga Polytechnic Examinations unit (2016).The Year 2010/2011 Shorthand Examination Chief Examiner's Report, Bolga

Bolgatanga Polytechnic Examinations unit (2016).The Year 2011/2012 Shorthand Examination Chief Examiner's Report, Bolga

Bolgatanga Polytechnic Examinations unit (2016).The Year 2012/2013 Shorthand Examination Chief Examiner's Report, Bolga

Bolgatanga Polytechnic Examinations unit (2016).The Year 2013/2014 Shorthand Examination Chief Examiner's Report, Bolga

Mugenda, A. \& Mugenda, O. (2003).Research methods; Quantitative and Qualitative approaches. African press for technology studies, Nairobi.

Ngechu, M. (2006).Understanding the research process and methods; Anintroduction.Report. University of Nairobi, Kenya.

\section{Internet Sources}

Adeyemi, J. K. (n.d.). Effect of teachers' academic qualification on students' performance at the secondary level. Retrieved from https://www.academia.edu/346972/Effect_of_teachers_academic_qualification_on_s tudents_Performance_at_the_secondary_level

Berly, p (n.d).What Is Pitman's Shorthand? Retrieved from https:// www.long-livepitmansshorthand.org.uk/blogspot-downloads.htm

Hong Kong Polytechnic (n.d.). Practical classes. Retrieved from http://www.polyu.edu.hk/learn-tolearn/es/materials/practical.pdf

John C. (2009): What is the role of practical activities in primary science teaching? Retrieved from http://www.aare.edu.au/02pgp/cri2222.htm

Miller R. (2004). The role of practical work in the teaching and learning of science. Retrieved from http://www.scribd.com/doc/11195279/The-role-of-practical-work-in-theteaching-and-learning-of-science

The Shorthand Place (n.d.) History of shorthand. Retrieved from http://www.tscript.co.uk/history.php

University of Wisconsin-Whitewater (n.d.).Identifying entry behaviours. Retrieved from http://facstaff.uww.edu/yinl/idsystem/tsld011.htm

Sweet, H. (2011). Amanual of current shorthand,Orthographic and phonetic. Retrieved from http://www .aare.edu.au/02pgp/cri2222.htm

White, P. J. (2009). The effects of the information explosion on information literacy. Retrieved from http://jacquelynpwhite.files.wordpress.com/2009/09/theeffectsoftheinformationexplosion oninformationliteracyedits-doc.pdf 